\title{
Performance characteristics of a gelled-electrolyte valve-regulated lead-acid battery
}

\author{
S K MARTHA, B HARIPRAKASH, S A GAFFOOR ${ }^{\dagger}$ and A K SHUKLA* \\ Solid State and Structural Chemistry Unit, Indian Institute of Science, Bangalore 560 012, India \\ ${ }^{\dagger}$ NED Energy Ltd., 6-3-1109/1 Navbharat Chambers, Raj Bhavan Road, Hyderabad 500 082, India
}

MS received 8 May 2003

\begin{abstract}
V/25 AH gelled-electrolyte valve-regulated lead-acid batteries have been assembled in-house and their performance studied in relation to the absorptive glass-microfibre valve-regulated and floodedelectrolyte counterparts at various discharge rates and temperatures between $-40^{\circ} \mathrm{C}$ and $40^{\circ} \mathrm{C}$. Although the performance of the gelled-electrolyte valve-regulated battery is similar to both the absorptive glass-microfibre valve-regulated and flooded-electrolyte lead-acid batteries at temperatures above $0^{\circ} \mathrm{C}$, it is superior to both the flooded-electrolyte and absorptive glass-microfibre valve-regulated lead-acid batteries at temperatures between $0^{\circ} \mathrm{C}$ and $-40^{\circ} \mathrm{C}$. The latter characteristic is attractive for expanding the application regime of valveregulated lead-acid batteries. The corrosion rate for the positive grids in the gelled-electrolyte is also lower than both the flooded-electrolyte and absorptive glass-microfibre configurations.
\end{abstract}

Keywords. Valve-regulated lead-acid (VRLA) batteries; Peukert plots; corrosion.

\section{Introduction}

The lead-acid battery is one of the most successful electrochemical systems ever developed, and no other battery is yet able to compete with the lead-acid batteries on cost grounds, although batteries based on other chemistries are rapidly catching up (Dell and Rand 2002). There are three types of lead-acid batteries in common use: (a) batteries with flooded or excess electrolyte, (b) low-maintenance lead-acid batteries with a large excess of electrolyte, and (c) batteries with immobilized electrolyte and a pressure-sensitive valve usually referred to as absorptive glass-microfibre (AGM) valve-regulated leadacid (VRLA) batteries.

The flooded-electrolyte lead-acid battery requires checking of specific gravity of the electrolyte, periodic addition of water to maintain electrolyte above the top of the plates, and recharge soon after the battery discharge to prevent hard sulfation that causes loss in battery capacity. The emission of acid fumes causes corrosion of metallic parts in the vicinity of the battery. The seepage of acid on the top cover of the battery leads to a leakage current resulting in increased self-discharge and ground-shunt hazards. To overcome these problems, AGM-VRLA batteries based on oxygen-recombination cycle (Guo et al 2001) have emerged. These batteries offer the freedom of battery placement, cyclability without the addition of water or checking the electrolyte spe-

\footnotetext{
*Author for correspondence
}

cific gravity, increased safety, and superior performance in some instances (Linden and Reddy 2002). But, both flooded-electrolyte (Sunu and Burrows 1981; Takahashi et al 1985; Shimpo et al 1990; Apateanu et al 1993; Richter 1993) and AGM-VRLA (Higashimoto et al 1989; Nakayama et al 1991) lead-acid batteries can suffer from acid stratification.

In recent years, the AGM-VRLA battery has advanced as a versatile and extremely reliable energy-storage device, and efforts have been expended to understand and develop the technological knowledge base for AGMVRLA batteries (Berndt 2001). By contrast, there has been comparatively little documented and published work on advancing the design, durability and performance characteristics of the gelled-electrolyte VRLA battery since its inception during mid-1960s in Germany by Sonnenschein GmbH (Newnham and Baldsing 1996, 1997). In the technical literature, the debate over the relative merits of gel and AGM type of VRLA batteries in terms of their electrical performance and service life in different applications continues, and the issue is by no means yet resolved (Dell and Rand 2002). It is generally accepted that gelled-electrolyte VRLA batteries experience less electrolyte-stratification under deep-discharge cycle applications such as those experienced in remotearea power supply applications (Newnham and Baldsing 1996, 1997). The gas-recombination efficiency of gelledelectrolyte VRLA cells stabilizes much slower than AGMVRLA cells. But once the oxygen-recombination cycle is established in a gelled-electrolyte VRLA cell, these cells are known to have significantly lower float currents with 
a concomitant decrease in water loss during their service life (Lambert et al 2002). Although the capacity per unit volume of the flooded-electrolyte lead-acid batteries is higher than the gelled-electrolyte VRLA batteries, the latter can provide reliable and totally maintenance-free service in many of the cycling applications, and particularly so in photovoltaic and motive-power applications (Strebe et al 1990; May and Lenain 1992; Tuphorn 1992). Significantly, gelled-electrolyte VRLA batteries require lesser overcharge to attain full state-of-charge which improves their cycling faradaic-efficiency and gassing is reduced to a level where the oxygen cycle can function efficiently (Lambert et al 2002).

In this communication, we report the performance characteristics of a gelled-electrolyte VRLA battery built in-house. It is found that while the performance of the gelled-electrolyte VRLA battery is similar to both the AGM-VRLA and flooded-electrolyte lead-acid batteries at temperatures above $0^{\circ} \mathrm{C}$, it is superior to both the AGM-VRLA and flooded-electrolyte lead-acid counterparts at temperatures between $0{ }^{\circ} \mathrm{C}$ and $-40^{\circ} \mathrm{C}$ at all discharge rates. It is noteworthy that the successful operation of VRLA batteries at cold and extremely cold temperatures is considered as a precondition for further expansion of their application regime (Häring and Giess 2003).

\section{Experimental}

12 V/25 AH gelled-electrolyte VRLA, AGM-VRLA, and flooded-electrolyte lead-acid batteries were assembled by stacking two positive plates (each $14 \mathrm{Ah}$ ) and three negative plates (each $12 \mathrm{Ah}$ ) in each cell. The plates were connected to the respective lugs and placed into a polypropylene container, which could withstand sulfuric acid environment without deterioration over prolonged duration up to about $100^{\circ} \mathrm{C}$. The cells were connected in series by group-burning to form the batteries. The batteries were made positive limited to facilitate oxygen recombination at the negative plates in the VRLA type batteries. The plate preparation in all three battery types studied here was kept identical for an accurate comparison of their performance.

The AGM-VRLA batteries were constructed by placing the AGM separator supplied by Nippon Sheet Glass Co., Japan in between the plates and strapping them with polythene bands followed by filling a required amount of $4.5 \mathrm{M}$ aqueous sulphuric acid in the cell containers, and the batteries were kept for about $2 \mathrm{~h}$ for electrolyte soaking. The flooded-electrolyte lead-acid batteries were assembled by inserting poly-vinyl chloride separator in between the plates, and filling $4.5 \mathrm{M}$ aqueous sulphuric acid to a level above the top of the plates in the containers. The flooded-electrolyte lead-acid batteries were also allowed about $2 \mathrm{~h}$ stand for electrolyte soaking. Both the battery types were formed by charging them galvano- statically at $\mathrm{C} / 10$ rate (current $=2.5 \mathrm{~A}$ ) followed by discharging at $\mathrm{C} / 5$ rate. The batteries were formed to their rated capacity within about three charge-discharge cycles. The gelled-electrolyte VRLA batteries were constructed by mixing $4.5 \mathrm{M}$ aqueous sulphuric acid and M-5 CAB-O-SIL ${ }^{\circledR}$ fumed silica to form a thixotropic gel, which is filled into all the six cell containers up to the upper level of the plates. Subsequently, the batteries were kept for about $12 \mathrm{~h}$ for the gel to form and settle. As the gel stiffens, it shrinks and this leads to formation of numerous micro-fine cracks through which the oxygen generated at the positive plates is able to diffuse to the negative plates. Unlike AGM-VRLA and flooded-electrolyte lead-acid batteries, gelled-electrolyte VRLA batteries were dry formed prior to the gel filling.

All the battery types were subsequently subjected to galvanostatic charge-discharge at various rates and temperatures ranging between $-40^{\circ} \mathrm{C}$ and $40^{\circ} \mathrm{C}$ using cold/ hot chambers. The charge-discharge studies on all the batteries were carried out using a Keithly 228 A Voltage/ Current Source interfaced to a data acquisition system. The data were initially collected at an interval of $1 \mathrm{~s}$ up to about $2 \mathrm{~min}$. Beyond two min of the battery discharge, data were collected for every $5 \mathrm{~min}$.

Grid-corrosion experiments on positive grids $(\mathrm{Pb}-\mathrm{Ca}-$ $\mathrm{Sn}-\mathrm{Al}$ alloy comprising of $0.1 \%$ of $\mathrm{Ca}, 1.2 \%$ of $\mathrm{Sn}$ and $0.03 \%$ of $\mathrm{Al}$ ), of the batteries were performed using one positive grid and two negative plates in each cell at $55^{\circ} \mathrm{C}$ with gelled-electrolyte, AGM and flooded-electrolyte configurations in a temperature controlled water bath. For this purpose, the grids were kept potentiostatically at $2.4 \mathrm{~V}$ for 21 days and the variations in the current were recorded continuously. Subsequently, the grids were removed and washed with de-ionized water. Dipping the grids in the red-lead extraction solution comprising sodium acetate trihydrate, potassium iodide and glacial acetic acid then stripped the corrosion layer on the grids. The grids were again washed copiously with de-ionized water and dried in a hot air oven at about $60^{\circ} \mathrm{C}$. The corrosion rates were determined from the weight loss of the grids. These experiments were also corroborated by conducting cyclic voltammetric studies on grids in gelledelectrolyte, AGM and flooded-electrolyte configurations employing an Autolab PGSTAT 30.

\section{Results and discussion}

Figures 1(a) and (b) depict a comparison between the charge and discharge characteristics at $\mathrm{C} / 5$ rate for the gelled-electrolyte VRLA, AGM-VRLA and floodedelectrolyte lead-acid batteries at $25^{\circ} \mathrm{C}$. From the data in figure 1(a), we find that the charging voltage for the gelled-electrolyte VRLA battery is relatively higher than both the AGM-VRLA and flooded-electrolyte lead-acid batteries. From the data in figure 1(b), it is evident that 
the discharge capacity values for the gelled-electrolyte VRLA and AGM-VRLA batteries are nearly similar. We have also studied the discharge behaviour of the gelledelectrolyte VRLA, AGM-VRLA and flooded-electrolyte lead-acid batteries at various discharge rates at $25^{\circ} \mathrm{C}$ and the capacity data as per cent of nominal capacity at $\mathrm{C} / 5$ rate are presented in figures 2(a), (b) and (c), respectively. We find that both the low rate and high rate discharge characteristics of all the three battery types are nearly identical at $25^{\circ} \mathrm{C}$. The data on battery voltages at various state-of-charge values for the gelled-electrolyte VRLA, AGM-VRLA and flooded-electrolyte lead-acid batteries are shown in figure 3 . The data show the voltages for the gelled-electrolyte VRLA battery to be higher at all state-of-charge values in relation to both the AGMVRLA and flooded-electrolyte lead-acid batteries.

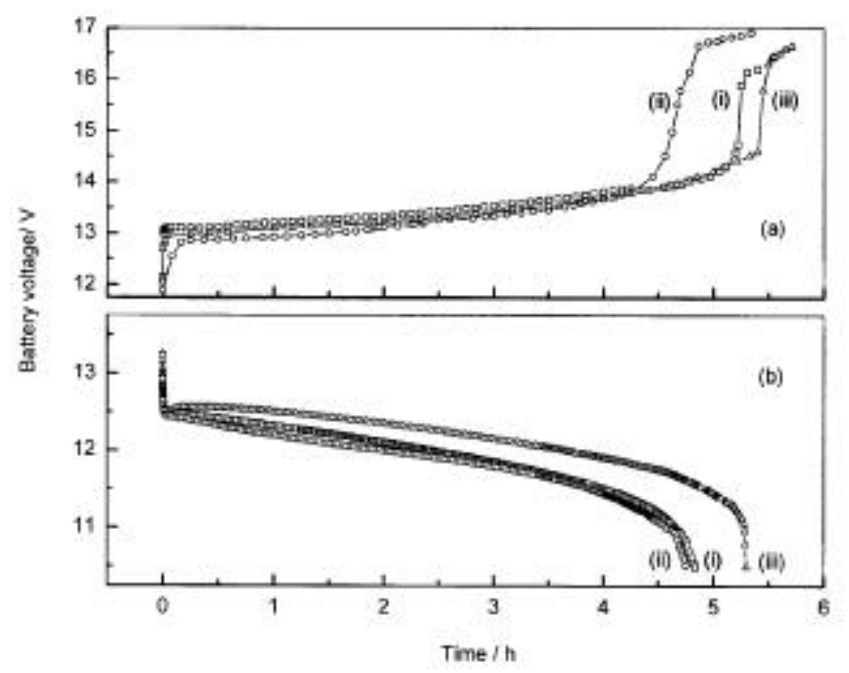

Figure 1. A comparison between (a) charge and (b) discharge characteristics of (i) gelled-electrolyte VRLA, (ii) AGM-VRLA, and (iii) flooded-electrolyte lead-acid batteries at $25^{\circ} \mathrm{C}$.

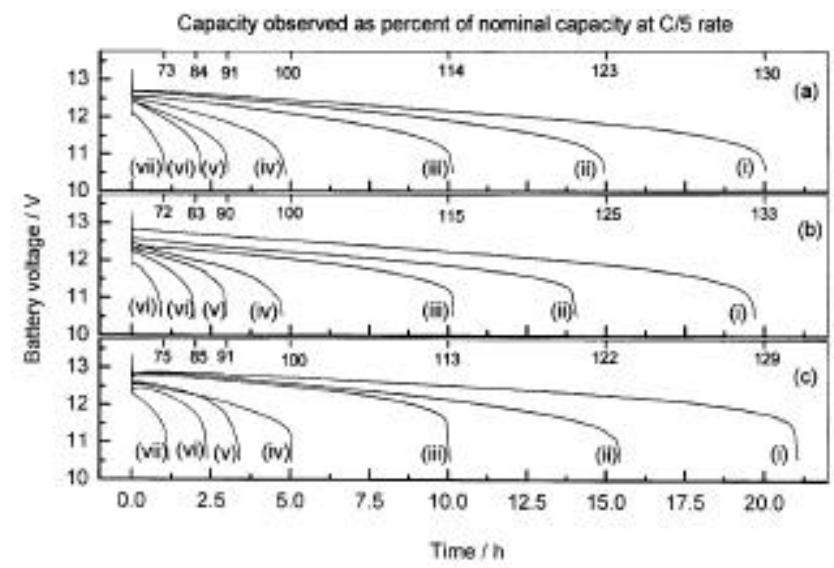

Figure 2. Discharge capacities for the (a) gelled-electrolyte VRLA, (b) AGM-VRLA, (c) flooded-electrolyte lead-acid batteries obtained at $25^{\circ} \mathrm{C}$ at (i) $\mathrm{C} / 20$, (ii) $\mathrm{C} / 15$, (iii) $\mathrm{C} / 10$, (iv) $\mathrm{C} / 5$, (v) $\mathrm{C} / 3$, (vi) $\mathrm{C} / 2$, and (vii) $\mathrm{C}$ rates.
The Peukert plots (Dell and Rand 2002) for the gelledelectrolyte VRLA, AGM-VRLA and flooded-electrolyte lead-acid batteries are shown in figures 4(a), (b) and (c), respectively. The data suggests that the service life of the gelled-electrolyte VRLA batteries under a particular discharge rate would be similar to those for AGM-VRLA and flooded-electrolyte lead-acid batteries. This also suggests that the weight and size of the gelled-electrolyte VRLA batteries could be kept identical to those of the AGM-VRLA and flooded-electrolyte lead-acid batteries. From these Peukert plots we have derived the values of $n$ in the Peukert relationship,

$$
I^{n} t=a
$$

where $I$ is the discharge current, $t$ the discharge time, and $a$ is a constant. The values of $n$ are found to be $0.8,0.78$ and 0.84 for the gelled-VRLA, AGM-VRLA and floodedelectrolyte lead-acid batteries, respectively. Since the values of $n$ are near 1 for all these batteries, the battery discharge process will have little inhibition. Similar values of $n$ have been reported by Strebe et al (1990).

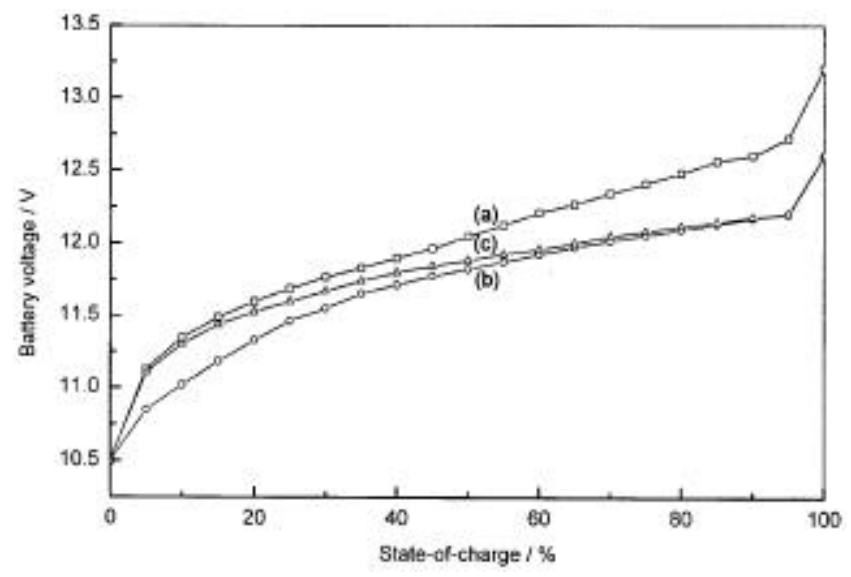

Figure 3. Variation in the voltages of (a) gelled-electrolyte VRLA, (b) AGM-VRLA, and (c) flooded-electrolyte lead-acid batteries as a function of their state-of-charge values.

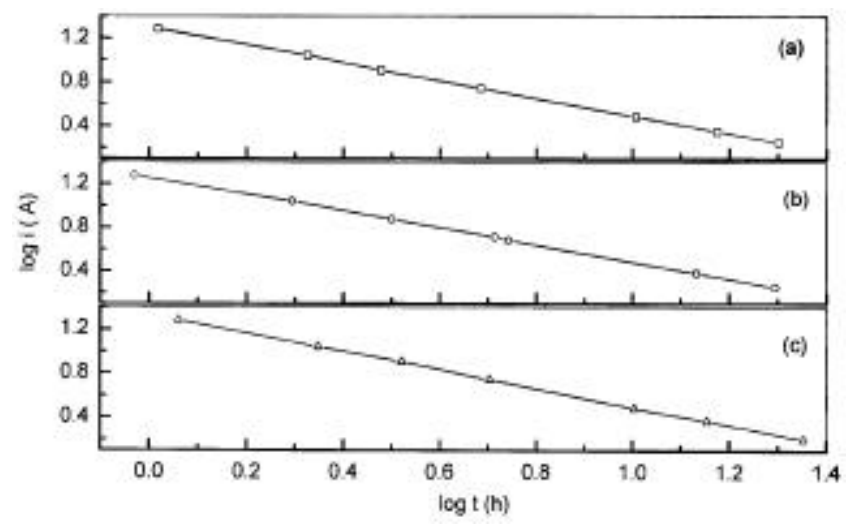

Figure 4. Peukert plots for (a) gelled-electrolyte VRLA, (b) AGM-VRLA, and (c) flooded-electrolyte lead-acid batteries at $25^{\circ} \mathrm{C}$. 
The data on the effect of temperature on the discharge characteristics of the gelled-electrolyte VRLA, AGMVRLA and flooded-electrolyte lead-acid batteries at $\mathrm{C} / 5$ and $\mathrm{C} / 10$ rates are given in figures 5 and 6 , respectively. Interestingly, the discharge capacities for the gelled-electrolyte VRLA batteries at both these rates are higher than the AGM-VRLA and flooded-electrolyte lead-acid batteries at temperatures between $0^{\circ} \mathrm{C}$ and $-40^{\circ} \mathrm{C}$. The performance of gelled-electrolyte VRLA batteries is similar to both AGM-VRLA and flooded-electrolyte lead-acid batteries at temperatures above $0^{\circ} \mathrm{C}$.

Since corrosion is a limiting factor for the performance of the lead-acid batteries, we have conducted corrosion studies on the positive grids in gelled-electrolyte, AGM and flooded-electrolyte configurations at $55^{\circ} \mathrm{C}$, and the data are shown in figure 7 . The data show a lesser corro-

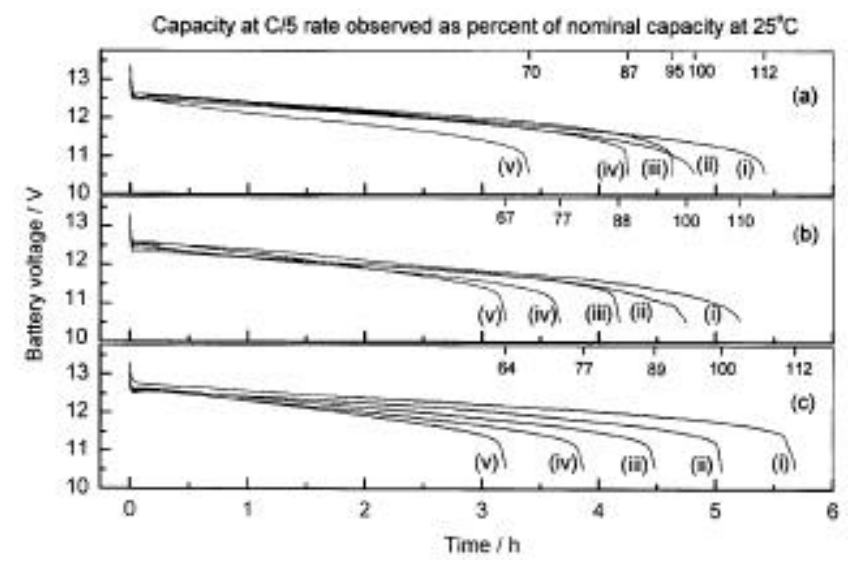

Figure 5. Effect of temperature on the discharge capacities for (a) gelled-electrolyte VRLA, (b) AGM-VRLA and (c) floodedelectrolyte lead-acid batteries at $\mathrm{C} / 5$ rate at (i) $40^{\circ} \mathrm{C}$, (ii) $25^{\circ} \mathrm{C}$, (iii) $0^{\circ} \mathrm{C}$, (iv) $-20^{\circ} \mathrm{C}$, and (v) $-40^{\circ} \mathrm{C}$.

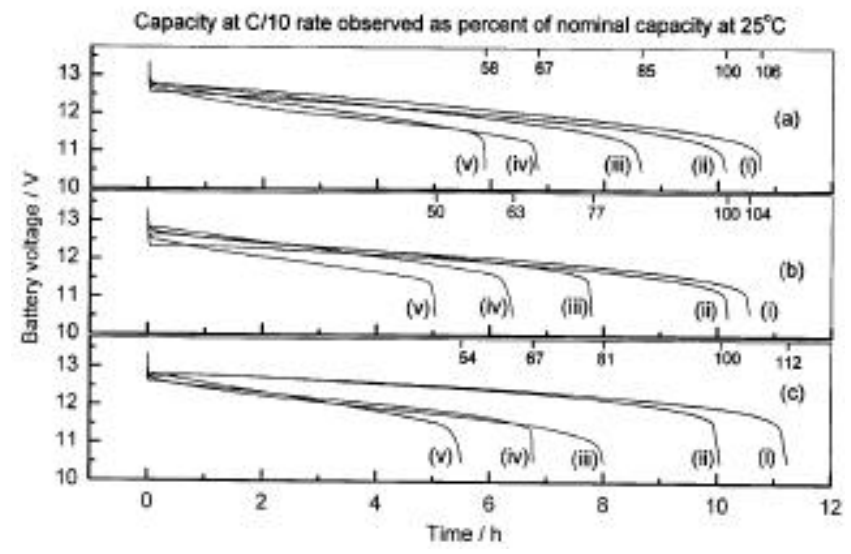

Figure 6. Effect of temperature on the discharge capacities for the (a) gelled-electrolyte VRLA, (b) AGM-VRLA and (c) flooded-electrolyte lead-acid batteries at $\mathrm{C} / 10$ rate at (i) $40^{\circ} \mathrm{C}$, (ii) $25^{\circ} \mathrm{C}$, (iii) $0{ }^{\circ} \mathrm{C}$, (iv) $-20^{\circ} \mathrm{C}$, and $(\mathrm{v})-40^{\circ} \mathrm{C}$. sion rate for the positive grids tested in the gelled-electrolyte. The corrosion rates obtained from the weight loss method for the positive grids in gelled-electrolyte, AGM and flooded-electrolyte configurations at $55^{\circ} \mathrm{C}$ are $6.94 \times$ $10^{-4}, 7.44 \times 10^{-4}$ and $8.43 \times 10^{-4} \mathrm{~g} / \mathrm{cm}^{2} /$ day, respectively. Cyclic voltammograms obtained on the grids in gelledelectrolyte, AGM and flooded-electrolyte configurations also exhibit similar trend (figure 8).

We have also conducted charge-discharge cycle-life tests at C/5 rate on the gelled-electrolyte VRLA, AGMVRLA and flooded-electrolyte lead-acid batteries at $25^{\circ} \mathrm{C}$ and the data are shown in figures 9(a), (b) and (c), respectively. Akin to the AGM-VRLA and flooded-electro-

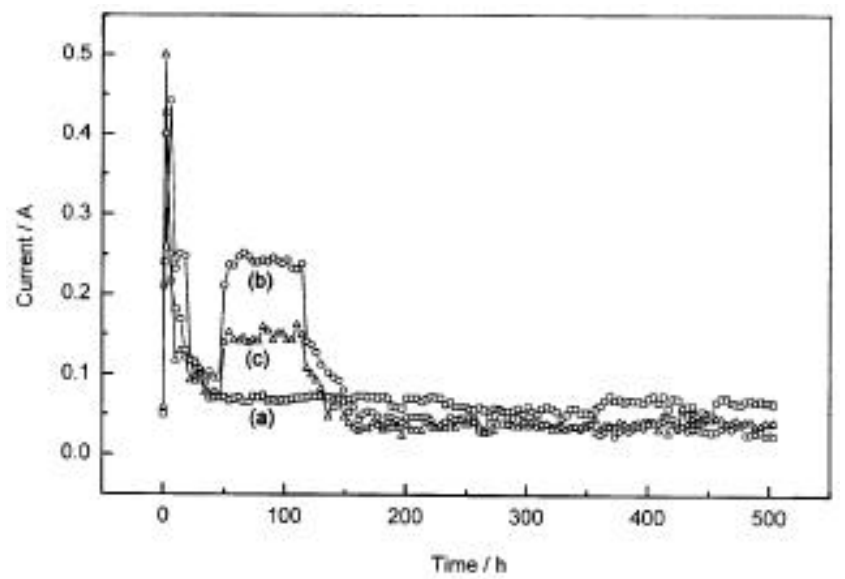

Figure 7. Potentiostatic corrosion data for the positive grids in the (a) gelled-electrolyte, (b) AGM, and (c) flooded-electrolyte configurations.

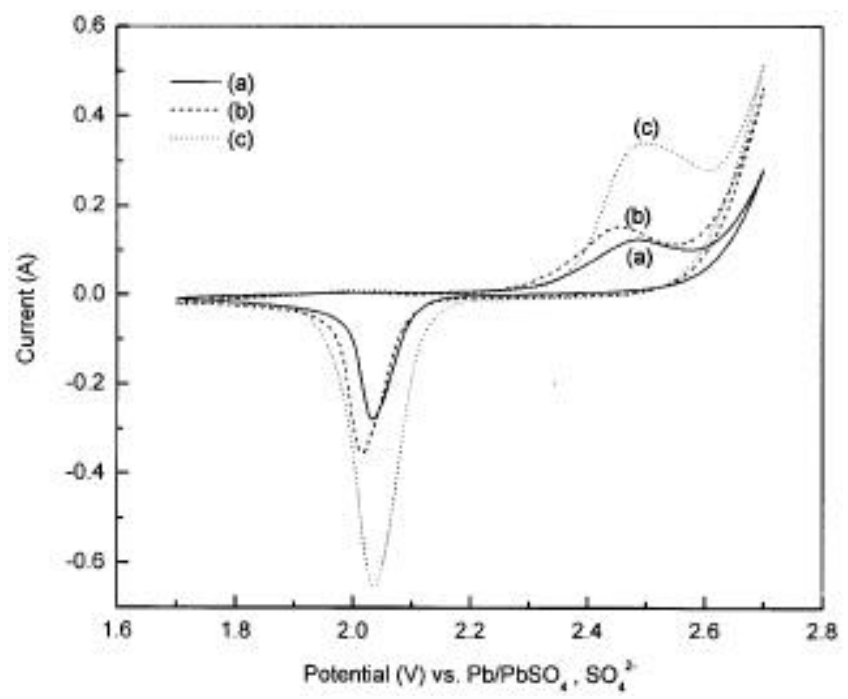

Figure 8. Cyclic voltammograms of grids obtained at $25^{\circ} \mathrm{C}$ in (a) gelled-electrolyte $\left(4.5 \mathrm{M} \mathrm{H}_{2} \mathrm{SO}_{4}\right)$, (b) AGM (4.5 $\left.\mathrm{M} \mathrm{H}_{2} \mathrm{SO}_{4}\right)$, and (c) flooded-electrolyte $\left(4.5 \mathrm{M} \mathrm{H}_{2} \mathrm{SO}_{4}\right)$ configurations (scan rate $=20 \mathrm{mV} \mathrm{s}^{-1}$ ). 


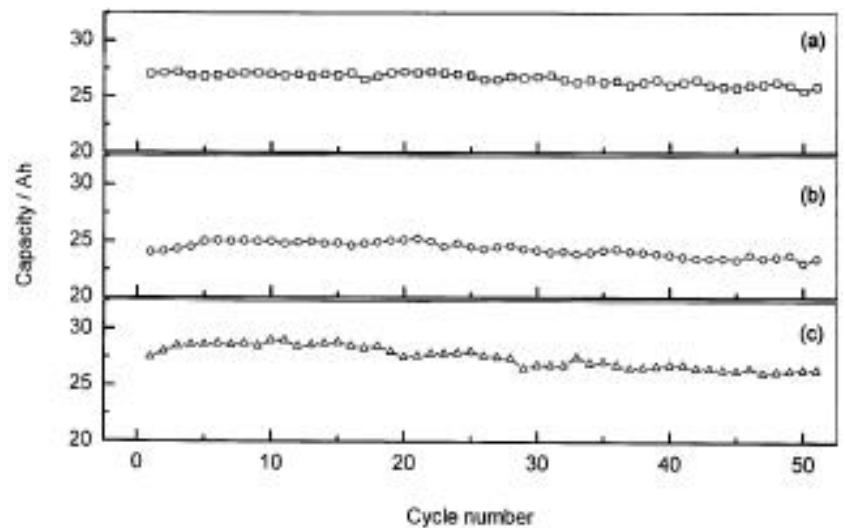

Figure 9. Cycle-life data for (a) gelled-electrolyte VRLA, (b) AGM-VRLA, and (c) flooded-electrolyte lead-acid batteries obtained at $\mathrm{C} / 5$ rate at $25^{\circ} \mathrm{C}$.

lyte lead-acid batteries, gelled-electrolyte VRLA batteries show little degradation in their rated capacity up to 50 cycles.

\section{Conclusions}

The performance of a gelled-electrolyte VRLA battery built in-house has been compared with its AGM-VRLA and flooded-electrolyte lead-acid battery counterparts. It is found that while the performance of gelled-electrolyte VRLA batteries is similar to both AGM-VRLA and flooded-electrolyte lead-acid batteries at temperatures above $0^{\circ} \mathrm{C}$, its performance is better than both AGMVRLA and flooded-electrolyte lead-acid batteries at temperatures between $0^{\circ} \mathrm{C}$ and $-40^{\circ} \mathrm{C}$. The latter characteristic of the gelled-electrolyte VRLA batteries is promising for expanding their application envelope.

\section{Acknowledgements}

We thank Mr N Gautam, NED Energy Ltd., Hyderabad for the kind encouragement and support during the course of this study. Financial assistance from DRDO is gratefully acknowledged.

\section{References}

Apateanu L, Hollenkamp A F and Koop M J 1993 J. Power Sources $\mathbf{4 6} 239$

Berndt D 2001 J. Power Sources 10029

Dell R M and Rand D A J 2002 Understanding batteries (Cambridge, UK: Royal Society of Chemistry)

Guo Y, Wu J, Song L, Perrin M, Doering H and Garche J 2001 J. Electrochem. Soc. 148 A1287

Häring P and Giess H 2003 J. Power Sources (in press)

Higashimoto K, Miura A, Hayakawa T and Komaki A 1989 Prog. Batteries \& Solar Cells $\mathbf{8} 268$

Lambert D W H, Greenwood P H J and Reed M C 2002 J. Power Sources 107173

Linden D and Reddy T B (eds) 2002 Handbook of batteries (NY: McGraw-Hill) 3rd ed.

May G J and Lenain P 1992 J. Power Sources 40187

Nakayama Y, Nagayasu T, Kishimoto K and Kasai Y 1991 Yuasa Jiho 7146

Newnham R H and Baldsing W G A 1996 J. Power Sources 59 137

Newnham R H and Baldsing W G A 1997 J. Power Sources 6627

Richter J 1993 J. Power Sources 42231

Shimpo M, Nakashima H, Sasabe S and Kasia Y 1990 Yuasa Jiho 6826

Strebe J, Reichman B, Mahato B and Bullock K R 1990 J. Power Sources 3143

Sunu W G and Burrows B R 1981 J. Electrochem. Soc. 128 1405

Takahashi K, Sagawa T and Tsubota M 1985 GS News 448

Tuphorn H 1992 J. Power Sources 4047 